\title{
Stereological Study on the Effects of Maternal Caffeine Consumption on Histomorphometric Changes of Testis and Prostate in Rat Offspring \\ Mahboubeh Belali kharaji ${ }^{1}$, Maryam Yadegari ${ }^{1 *}$, Mohammad Hosseini Sharifabad ${ }^{1}$, Morteza Anvari $^{1}$, Abolghasem Abbasi Sarcheshmeh ${ }^{1}$, Hengameh Dortaj ${ }^{1}$
}

1. Anatomy and Cell Biology, Shahid Sadoughi University of Medical Sciences, Yazd, Iran

\begin{tabular}{c} 
KEYWORDS \\
\hline Caffeine; \\
Testis; \\
Prostate; \\
Stereology; \\
Rat offspring \\
\hline Article Info \\
\hline
\end{tabular}

Received 2019/01/2;

Accepted 2019/02/10;

Published Online 2020

\section{ABSTRACT}

Background and Objective: It is conceivable that caffeine consumption would induce gonadal changes. The aim of this study is to assess the impact of embryonic caffeine exposure on rat testis and prostate.

Materials and Methods: Female rats were divided into $(n=7)$ : A control, only received drinking water. $B$ and $C$ groups received caffeine low dose $(26 \mathrm{mg} / \mathrm{kg})$ and high dose $(45 \mathrm{mg} / \mathrm{kg})$ respectively via drinking water during pregnancy and lactation. Structural changes in testis and prostate were studied by using stereological methods at 21, 60 and 120 days of postnatal development.

Results: Our result showed decreases in body and testis weight of offspring of group $\mathrm{C}$ compared to other groups at all ages $(\mathrm{P}<0.05)$. The Testis volume showed significant differences between the offspring of both experimental groups and control at days 21,60 and $120(\mathrm{P}<0.05)$. There were significant differences in the number of sperm cells of offspring of experimental groups compared to the control group in different ages $(\mathrm{P}<0.05)$. The number of sertoli, spermatocyte and spermatid cells of offspring in group $\mathrm{C}$ showed a significant decrease compared with other groups at all days $(\mathrm{P}<0.01)$. The number of spermatogonia cells in group $\mathrm{C}$ offspring showed a significant decrease compared to the control group at different days $(\mathrm{P}<0.05)$. The mean Johnsen score decreased in offspring of group $\mathrm{C}$ compared to the control group $(\mathrm{P}<0.05)$.

Conclusion: Results showed that maternal caffeine consumption altered the structure of testis and prostate gland and spermatogenesis of offspring in adulthood.

\footnotetext{
Corresponding Information: Maryam Yadegari., Anatomy and Cell Biology, Shahid Sadoughi University of Medical Sciences, Yazd, Iran , E-mail: yadegari_m@yahoo.com
}

Copyright $($ ) 2020. This is an open-access article distributed under the terms of the Creative Commons Attribution-noncommercial 4.0 International License which permits copy and redistribute the material just in noncommercial usages, provided the original work is properly cited.

\section{Introduction}

Today, infertility is a great problem in $15-20 \%$ of couples who are at the age of reproduction. In $50 \%$ of cases, men are the cause of infertility [1]. It has been reported that exposure to some environmental, chemical and biological agents induced irreversible effect on the reproductive system and fertility [2]. During recent decades, caffeine has been implicated as a risk factor for infertility [3]. The minor caffeine metabolite is 1, 3, 7-Trimethyluric acid [4]. Caffeine is a bitter tasting, odorless and white crystalline purine and is chemically related to the guanine and adenine bases of deoxyribonucleic acid (DNA) and ribonucleic acid (RNA). Caffeine may be synthesized in the laboratory with malonic acid and dimethylurea, but is not usually manufactured synthetically [5] and is it mainly extracted from 
seeds, nuts, or leaves of a number of plants [6]. The main sources of dietary caffeine are roasted coffee beans and tea leaves, with each contributing about equally to total caffeine intake (about $240 \mathrm{mg} /$ day) [7]. When caffeine is consumed, $99 \%$ of it is rapidly absorbed by the digestive tract and then metabolized in the liver into three primary metabolites: paraxanthine $(84 \%)$, theobromine $(12 \%)$, and theophylline (4\%) [8]. Caffeine's half-life in healthy adults, is between 3-7 hours. However, in pregnant woman it is between 9-11 hours and in infants is between 65-130 hours [9, 10]. Because caffeine is both water- and lipid-soluble it easily crosses the placenta, therefore its concentration in the fetus is the same as it in the mother's plasma [11]. The fetus' liver lacks enzymes to caffeine metabolism [12]. Some studies indicated that the consumption of caffeine increases the risk of spontaneous abortion, especially in the first trimester of pregnancy and increases the risk of stillbirth and low birth weight (LBW) [13]. A substantial number of human and animal studies indicated that caffeine can be toxic for the male reproductive system $[14,15]$. Caffeine can induce testicular atrophy and decrease spermatogenesis in adult animals [16]. In addition, gestational and lactational exposure of rats to caffeine had adverse effects on the structure and size of the testis, serum testosterone levels, and the fertility of male offspring [17]. Caffeine can lead to delayed sexual maturation by decreasing the production of testosterone [18]. On the other hand, moderate caffeine consumption appears to be safe to male reproductive health since it stimulates lactate production by sertoli cells; lactate is the primary source for energy production in spermatogeneic cells [19]. Chronic caffeine exposure of rats increases the androgenic hormones, concentrations of testosterone and dihydrotestosterone and epithelial cell proliferation in the prostate gland, which can lead to benign prostatic hyperplasia[20]. Another study concluded that there is no significant relationship between the consumption of caffeine and prostate cancer aggressiveness [21]. Although there are substantial numbers of studies on caffeine effects, but the exact activity of caffeine on the male reproductive system has been less characterized [17, 22]. The caffeine effects on the male reproductive system can be better assessed by prolonging the duration of the study (both exposure to caffeine and discontinuation period) and investigating the effects of caffeine from birth until post-puberty. Therefore; in this study we investigated the effect of gestational and lactation exposure of caffeine on spermatogenesis and histomorphometric changes of the testis and prostate in male offspring's rats at 21, 60 and 120 days after birth.

\section{Material and Methods \\ Chemicals}

The Caffeine, hematoxylin and eosin was obtained from Sigma. Other chemicals such as Azocarmine B and Aniline orange $\mathrm{G}$ were obtained from Santa Cruz biotechnology.

\section{Animals}

21 Female Wistar rats weighing 240-270 gr were obtained from the animal house of Shahid Sadoughi University of Medical Sciences Yazd - Iran. Female rats were allowed to acclimate under controlled humidity (40-50\%), temperature $\left(22-24^{\circ} \mathrm{C}\right)$, and light conditions (12-hr light-dark cycle) and had free access to rat food and tap water.

\section{Experimental Design}

After a week of adaptation to the environment, female rats were mated overnight at 3:1 females: male ratio. Vaginal smears were collected daily and examined for the presence of sperm. The day of sperm detection in the vaginal smears was considered 0 day of pregnancy. The pregnant rats were randomly divided into three groups $(n=7)$ : a control group only received drinking water and two experimental groups were exposed to low and high doses $(26,45 \mathrm{mg} / \mathrm{kg} /$ day $)$ of caffeine via drinking water during gestation and lactation[17]. According to previous studies, these doses were selected in a range that could have behavioral effects on the offspring of rats exposed to caffeine doses during gestation and lactation. It is also reported that feeding $\geq 30 \mathrm{mg} / \mathrm{kg} /$ day of caffeine can be harmful for the reproductive system of male rats [17]. The pregnant rats were kept separately in standard cages and the dose of caffeine was calculated by measuring daily water intake of each rat. At 21, 60 and 120 days after birth, five animals from each group were randomly selected and evaluated for each type of clinical signs, and their weight and nutrition were measured daily as well. The study took 120 days as the longest time to find out what 
long-lasting effects of caffeine on the testis and prostate might be. All the animals were anesthetized with ether $24 \mathrm{~h}$ after their last time receiving caffeine. All this procedure used were was based on approved protocols of the Ethical Committee of Shahid Sadoughi University of Medical Sciences Yazd - Iran.

Tissue Preparation and Histological Analysis of Testis and Prostate

On days 21, 60 and 120 of postnatal development, the rat offspring were weighed and anesthetized by diethyl ether. The testes and prostates were dissected. The left testis and prostate of each rat was weighted by an analytic scale with precision of $0.001 \mathrm{gr}$. The initial volume of testes was calculated using the Archimedes principle, by immersion in distilled water [23]. The testes and prostates were fixed in Bouin's and formalin solution for tissue processing and studied using stereological methods. Then, tissues were processed for paraffin embedding and sectioning. Serial sections of $5 \mu \mathrm{m}$ thickness, with a certain distance, were taken from each testis and stained with hematoxylin and eosin (H\&E) and Heidenhain's Azan. The stained sections were studied under light microscopy (Olympus Japan) magnification $40 \times, 100 \times, 200 \times$ and $400 \times$ to evaluate spermatogenesis and histopathological changes of prostate.

Johnsen's score was used to categorize the spermatogenesis. This method applies a score of 110 for each tubule cross section examined (Table 1). The germinal epithelium of at least 50-60 tubules was assessed for each testis and the mean Johnsen's Score per rat was calculated [13].

\section{Results}

As it is said in numerous studies, S. typhi has a high-power pathogenicity and also can be transferred quickly from one person to another. Therefore, typhoid fever is one of the most remarkable diseases in the world [8]. Many factors are involved in the pathogenesis of bacteria specially S. typhi [9]. One of these factors is toxin-antitoxin (TA) system which has been considered today [7].

Since the TA system plays an essential role in the pathogenesis of bacteria [10], we decided to analyze the potent TA loci by bioinformatics method.

After reviewing two different species of S. typhi, it was shown that both species have numerous and different potent TA loci. In species $S$. typhi_P_stx in different categories we can see potent TA loci (Table 2). But more importantly, this potent TA loci is in categories $50-60 \%$ (Table 2).

The important issue is that among all unknown potent TA loci, hth-xre is present in most categories with the highest number compared to the other unknown potent TA loci (Table 2).

On the other hand, at categories $70-80 \%$, numerous unknown potent TA loci were found. In the species $S$. typhi_P_stx, hth-xre is also seen in most categories.

This can be considered as a potent TA locus as it has the highest number (Table 1). These analyses were performed to identify the potent TA loci in different species of S. typhi, so that better prediction of TA loci and clinical experiments become possible (Table 3, Figure 1).

Table 1. Modified Johnsen score

\begin{tabular}{|c|l|}
\hline Score & \multicolumn{1}{|c|}{ Score Description } \\
\hline 10 & Complete spermatogenesis and perfect tubule \\
\hline 9 & Slightly impaired spermatogenesis, many late spermatids, disorganized epithelium \\
\hline 8 & Less than five spermatozoa per tubule, few late spermatids \\
\hline 7 & No spermatozoa, No late spermatids, many early spermatids \\
\hline 6 & Few early spermatids, arrest of spermatogenesis at the spermatid stage, disturbance of spermatid differentiation \\
\hline 5 & No spermatids, many spermatocytes \\
\hline 4 & Few spermatocytes, arrest of spermatogenesis at the primary spermatocyte stage \\
\hline 3 & Spermatogonia only \\
\hline 2 & No germ cells, sertoli cells only \\
\hline 1 & No germ cell or sertoli cells, tubular sclerosis \\
\hline
\end{tabular}




\section{Heidenhain's Azan Staining}

In stereological studies on the testis, heidenhain's Azan staining is used because this technique makes the nucleus of the cells red and clear, cytoplasm pale pink and the connective tissue decolorized [23, 24]. Therefore, the cells are being completely identified and can be investigated and counted.

\section{Heidenhain's Azan Technique}

The tissues were stained in Azocarmine B solution for 15 minutes at room temperature and rinsed in distilled water. Then, the testes were stained in Aniline for 2 seconds. The samples were put in glacial acetic acid for 5 seconds, phosphotungstic acid for 2-3 minutes and Aniline blue-orange G-acetic solution for 5 minutes and rinsed in distilled water. Digital histographic images were captured using by invert microscopy (magnification 40×, 100×, 200×, 400×).

\section{Stereological Analysis of Testis The Volume of} Testis (mm3)

Cavalierian's technique was used to determine the total size and volume of the testes. Following histological processing, paraffin testes blocks were sectioned in identity with systematic random sampling. For this purpose serial sections with a certain thickness $(t)$, and a certain distance (d), were taken from each testis. In this technique, a grid counting point with $100 \mu$ distance between two points was randomly placed on the images (since the points are lacking dimension, we used a grid with a network of crosses (+)) (fig. 1).

Then, hitting points on the surface of the biopsy were counted and the total volume of each testis was calculated using the following formula:

$$
V=t \times a(p) \times \sum p / M^{2}
$$

Where $\mathrm{V}$ refers to the total volume of testis, $\mathrm{t}$ is the section thickness, $\mathrm{a}(\mathrm{p})$ is the area of one point $(1000 \mu), \Sigma \mathrm{P}$ is the total number of points counted in the component of interest, and $\mathrm{M}$ is the linear magnification [25].
No shrinkage correction was used in the study because of the insignificant magnitude of the shrinkage, and because no difference in shrinkage was found between groups.

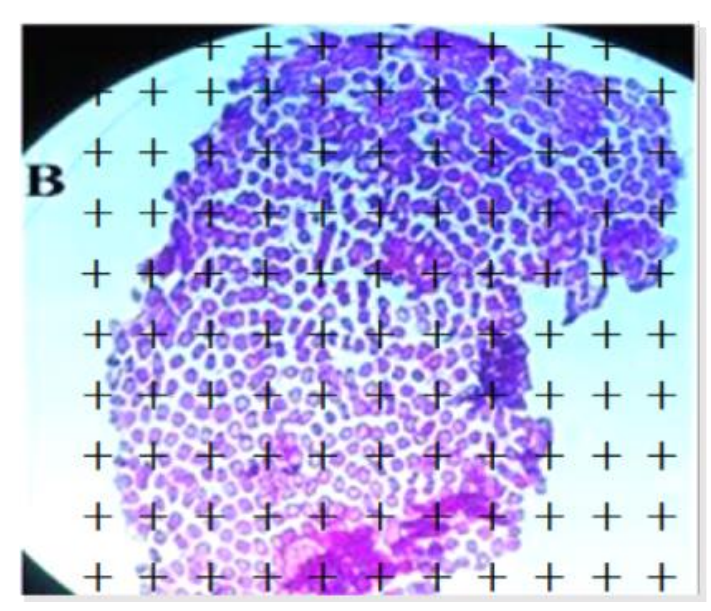

Fig. 1. Grid counting point and image of testis volume (magnification 40x) B: low dose group.

\section{The Number of Sertoli, Spermatogonia, Spermatocyte, Spermatid and Sperm Cells}

Physical dissector technique was used to count the number of sertoli, spermatogonia, spermatocyte, spermatid and sperm cells. A dissector is a 3D probe for counting the number of objects (cells), with the ability to remain unaffected by the size, shape, or spatial position of the objects. The first chosen section and its adjacent section, called a dissector pair, were separated by a distance of $30 \mu$ as a rule of physical dissector. According to this rule, the distance between the section pairs must be about $30-40 \%$ of the average projected height of the object of interest (in this study cell nucleus) to be estimated. This way, 20 section pairs from any biopsy were chosen and investigated [26]. A "live" image of a field from one section (say the sampled or reference section) is displayed on a monitor next to a stored image of the same field on the look-up section. The counting process requires the investigator to look for nuclei of immune stained cells in the sampled section that are not present in the look-up section (fig. 2). This development represents a powerful new method for counting defined cell populations in the testis [25]. 


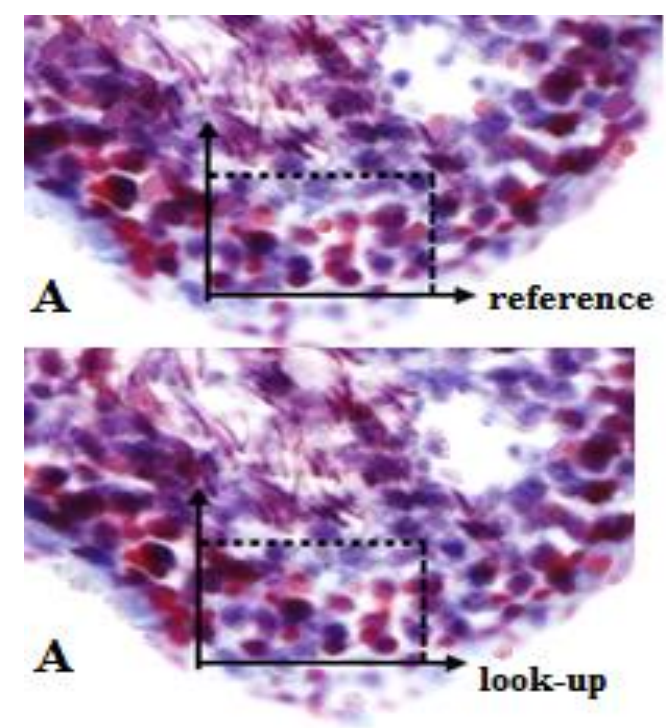

Fig. 2. Physical dissector and cells counting process, A: control group

The mean numerical density of cells was estimated using the following formula:

$$
N V=\Sigma Q / t \times a(p) \times h \times p
$$

Where $\Sigma \mathrm{Q}$ is the total number of cells counted in the reference section, it is the mean section thickness $(5 \mu)$ and a $(p)$ is the area of the unbiased counting frame, $h$ is the distance between sections and $\mathrm{P}$ is the number of frame associated points hitting the tissue.

The total number of cells in a whole rat testis was estimated by the following equation:

$$
T n=V n \times V t
$$

Where Nv is the numerical density of cells, Tn is total number of cells in the whole testis calculated using the testis volume results estimated by the Cavalieri method [26].

2.5.3. Assay histopathology changes of prostate
The Sections of $5 \mu \mathrm{m}$ thickness were taken from each prostate and stained with hematoxylin and eosin (H\&E). Each slide had sections from one region of the prostate, either the ventral prostate (VP) or the dorsolateral prostate (DLP). The stained sections were studied under light microscopy (Olympus Japan) magnification 100x and 400x. Measurements of the mean area of each of the alveoli and the height of epithelial cells were compiled.

\subsection{Statistical analysis}

Two-way analysis of variance (ANOVA) was used to compare the groups. When a significant interaction was detected, one-way ANOVA followed by the Tukey test in order to distinguish the difference among groups.

\section{Results}

The Mean Body Weight (gr) and Mean Testis Weight (mg) in Different Stages of Postnatal Development

Significant reductions were seen in the body weight of offspring of the high dose caffeine treated group compared to the control group and the low dose caffeine treated group at all ages of postnatal development (21, 60 and 120 days after birth) $(P<$ 0.05) (Fig. 3). The testis weight of the offspring were significantly lower in the high dose caffeine treated group $(P<0.05)$ compared with the control group at days 60 and 120 of postnatal development (Fig. 4).

The Mean Total Volume of Testis in Different Stages of Postnatal Development

The total volume of testis showed significant differences between the offspring of the experimental groups and the control group at postnatal day $21(\mathrm{P}<0.05)$, but this parameter in the offspring of high dose caffeine-treated groups has significantly decreased in comparison with the other group at days 60 and $120(\mathrm{P}<0.05)($ Fig. 5). 


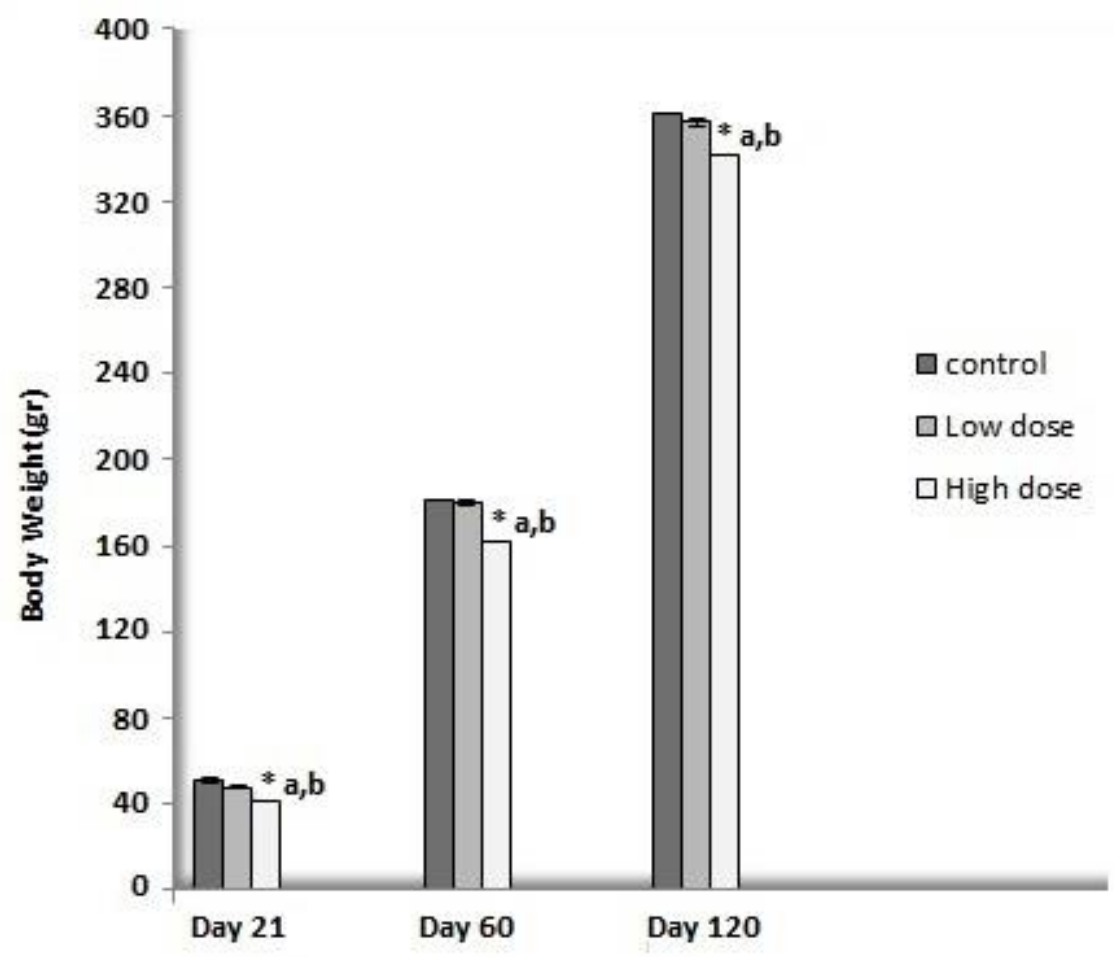

Fig. 3. Mean body weight (gr) at the postnatal days 21, 60, and 120 . $P<0.05$ is indicated by"*". Comparison between control and other groups (a), comparison between low dose caffeine treated group and other groups (b) and high dose caffeine treated group and other groups(c)

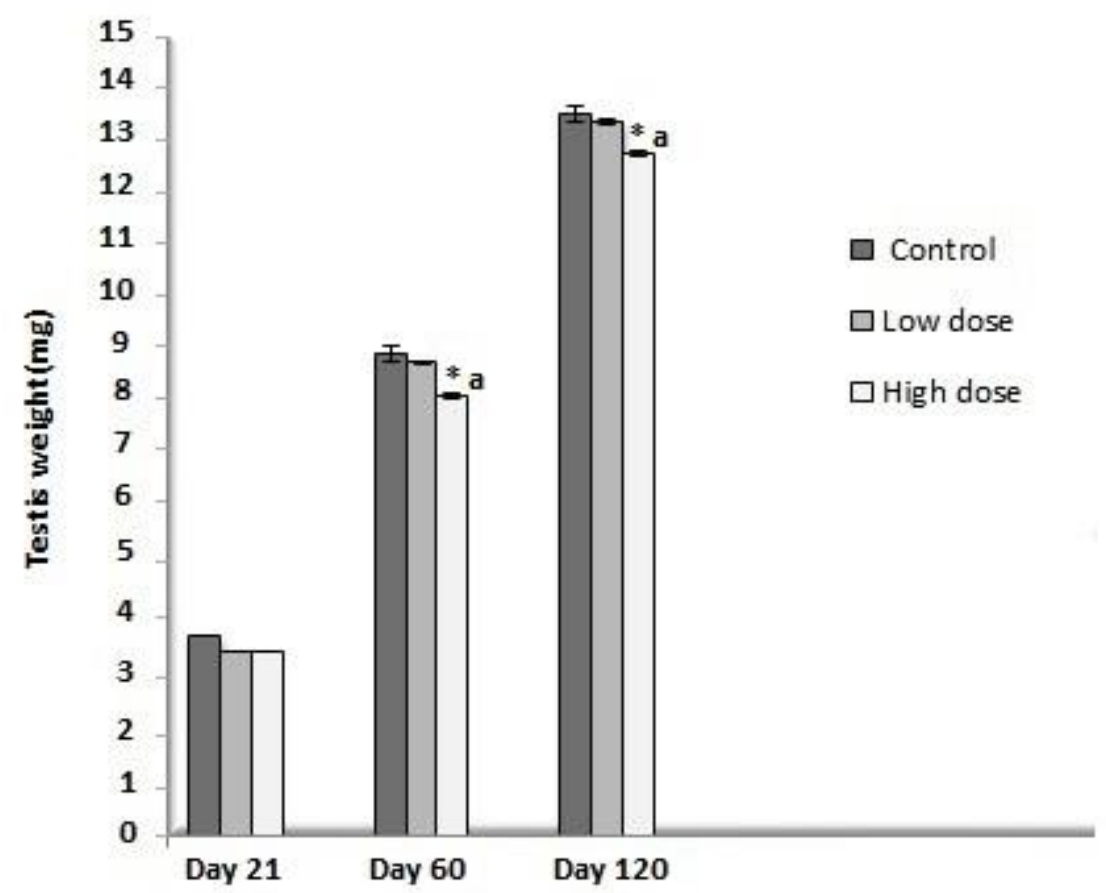

Fig. 4. Mean testis weight at the postnatal days 21, 60, and 120. P<0.05 is indicated by"*" Comparison between control and other groups (a), comparison between low dose caffeine treated group and other groups (b) and high dose caffeine treated group and other groups (c) 


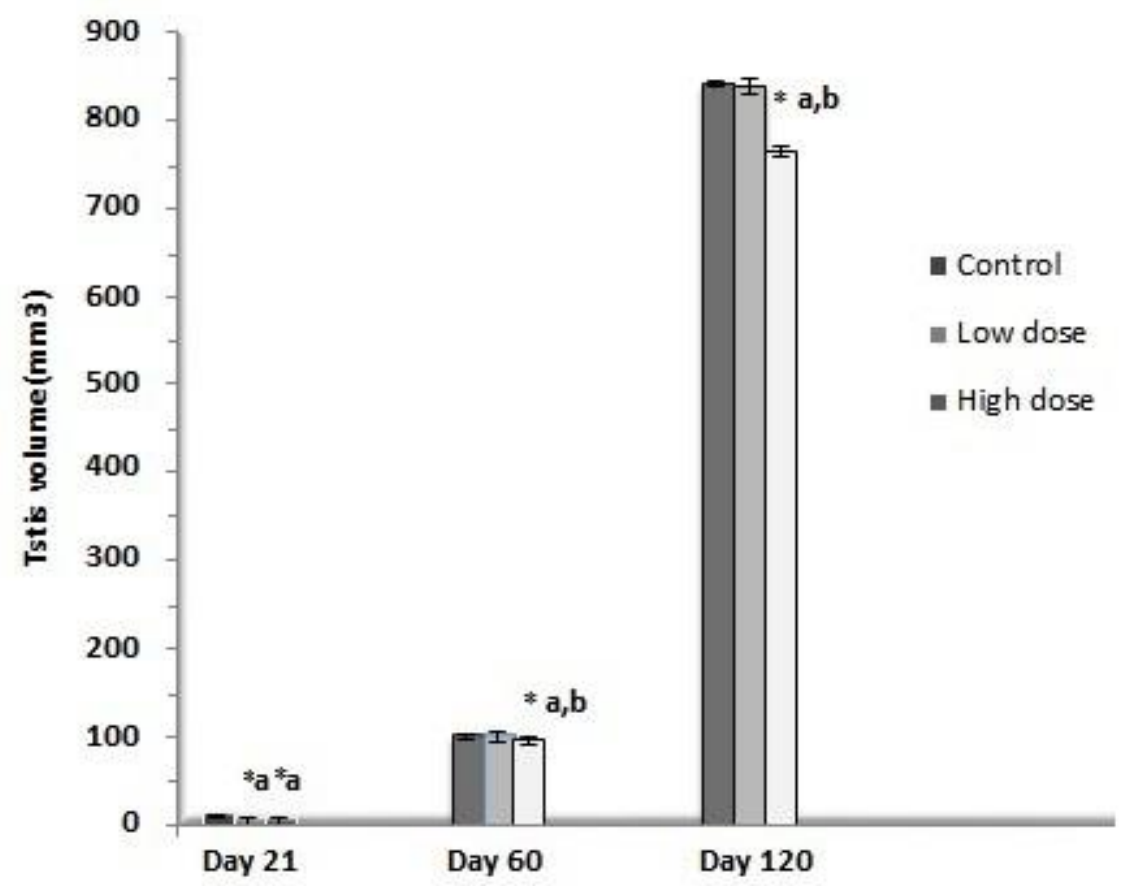

Fig. 5. Mean volume of testis ( $\mathrm{mm} 3$ ) at the postnatal days 21, 60, and 120. P<0.05 is indicated by"*". Comparison between control and other groups (a), comparison between low dose caffeine treated group and other groups (b) and high dose caffeine treated group and other groups (c)

Estimated Number of Sertoli, Spermatogonia, Spermatocyte, Spermatid and Sperm Cells

The total number of sperms cells in offspring of both experimental groups showed a significant decrease in comparison with the control group in day 120 of the postnatal. But the number of the cells in days 21 and 60 significantly reduced only in the high dose caffeine-treated group in comparison with the control group $(P<0.05)$. The total number of sertoli, spermatogonia, spermatocyte, and spermatid of offspring of the high dose group showed a significant decrease in comparison with the control and the low dose caffeine treated group in days 21, 60 and 120 (Fig. 6 and Table 2).

Table 2: Estimated number of sertoli, spermatogonia, spermatocyte, spermatid and sperm cells at the postnatal days 21,60 , and 120 .

\begin{tabular}{|c|c|c|c|c|}
\hline \multirow{3}{*}{ Parameters } & \multirow{3}{*}{ Age of offspring (day) } & \multicolumn{3}{|c|}{ Groups } \\
\hline & & \multirow{2}{*}{ Control } & \multicolumn{2}{|c|}{ Caffeine treated } \\
\hline & & & Low dose & High dose \\
\hline Sertoli number & $\begin{array}{c}21 \\
60 \\
120\end{array}$ & $\begin{array}{c}2.25 \pm 0.14 \\
3.4 \pm 0.18 \\
3.68 \pm 0.16\end{array}$ & $\begin{array}{c}2.11 \pm 0.66 \\
3 \pm 0.11 \\
3.72 \pm 0.24\end{array}$ & $\begin{array}{c}1.32 \pm 022 * * a, b \\
2 \pm 0.17 * * a, b \\
2.18 \pm 0.12 * * a, b\end{array}$ \\
\hline Spermatogonia number & $\begin{array}{c}21 \\
60 \\
120\end{array}$ & $\begin{array}{l}2.52 \pm 0.52 \\
3.12 \pm 0.44 \\
3.35 \pm 0.19\end{array}$ & $\begin{array}{c}2.33 \pm 0.15 \\
3.1 \pm 0.22 \\
2.99 \pm 0.29\end{array}$ & $\begin{array}{l}1.64 \pm 0.11 * \mathrm{a}, \mathrm{b} \\
2.18 \pm 0.19 * \mathrm{a}, \mathrm{b} \\
2.47 \pm 0.14 * \mathrm{a}, \mathrm{b}\end{array}$ \\
\hline Spermatocyte number & $\begin{array}{c}21 \\
60 \\
120\end{array}$ & $\begin{array}{l}22.33 \pm 011 \\
75.32 \pm 0.14 \\
114.98 \pm 0.1\end{array}$ & $\begin{array}{c}22 \pm 077 \\
75.44 \pm 0.22 \\
112.68 \pm 0.21\end{array}$ & $\begin{array}{c}21.1 \pm 0.28 * * a, b \\
72.25 \pm 1.2 * * a, b \\
104.77 \pm 0.15 * * a, b\end{array}$ \\
\hline Spermatid number & $\begin{array}{c}21 \\
60 \\
120\end{array}$ & $\begin{array}{c}2.1 \pm 0.7 \\
2.74 \pm 0.13 \\
3.64 \pm 0.16\end{array}$ & $\begin{array}{l}1.58 \pm 0.33 \\
2.50 \pm 0.41 \\
3.21 \pm 0.22\end{array}$ & $\begin{array}{c}1 \pm 0.11 * * a, \mathrm{~b} \\
2.1 \pm 0.33 * * \mathrm{a}, \mathrm{b} \\
2.64 \pm 0.13 * * \mathrm{a}, \mathrm{b}\end{array}$ \\
\hline Sperm number & $\begin{array}{c}21 \\
60 \\
120\end{array}$ & $\begin{array}{c}2.32 \pm 0.4 \\
3.67 \pm 0.12 \\
5.52 \pm 0.28\end{array}$ & $\begin{array}{c}2.10 \pm 0.22 \\
3 \pm 1.1 \\
2.95 \pm 0.18 * a\end{array}$ & $\begin{array}{c}1.40 \pm 0.55 * a \\
2.1 \pm 0.14 * a \\
2.18 \pm 0.14 * a\end{array}$ \\
\hline
\end{tabular}




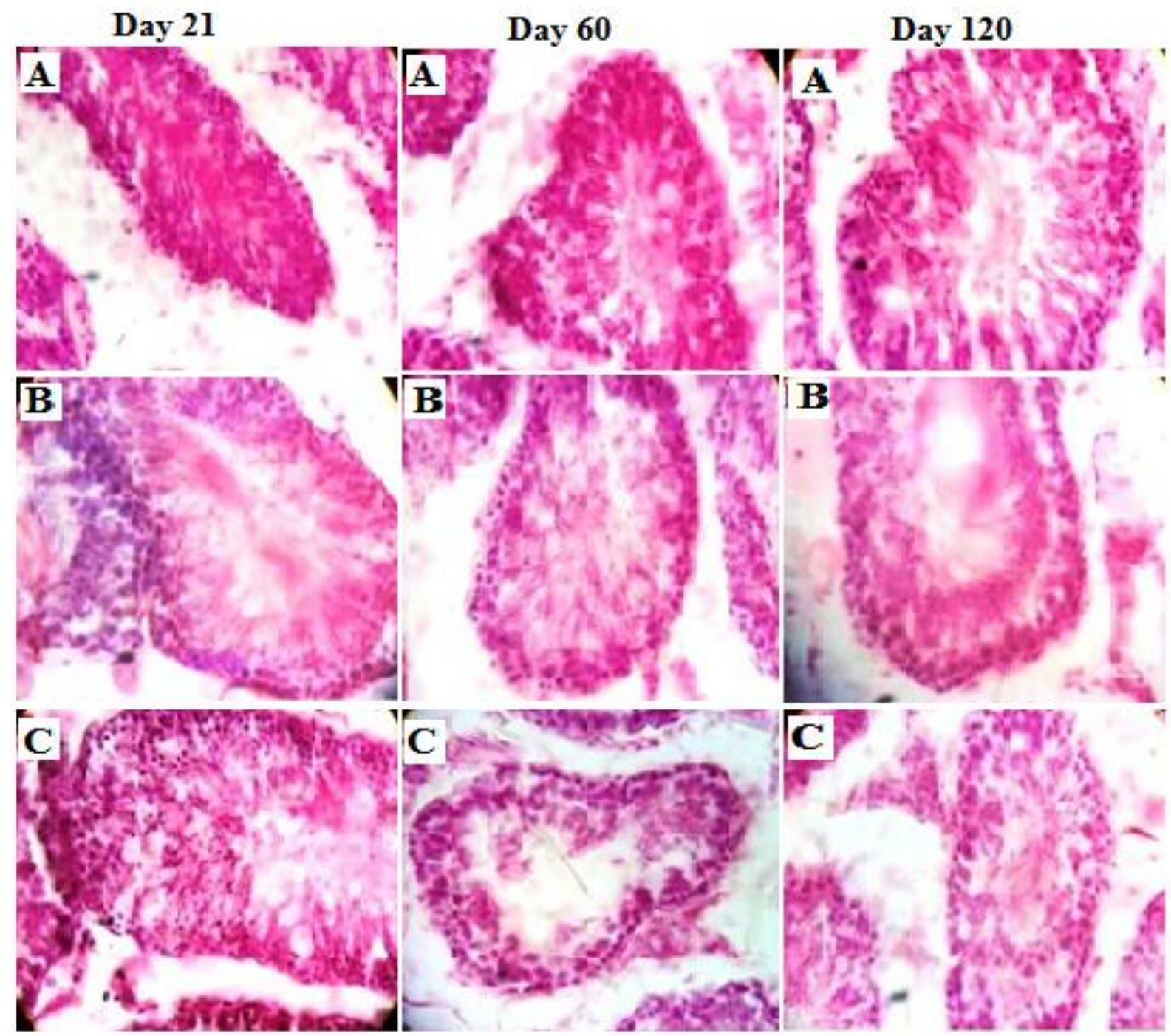

Fig. 6. Testis histopathological changes and estimation number of sertoli, spermatogonia, spermatocyte, spermatid and sperm cells at the postnatal days 21, 60, and 120. A control, B low dose caffeine and C high dose caffeine groups respectively (200x, H\&E).

\section{Johnsen Score Results}

In the histopathologic evaluation, the mean Johnsen score was decreased in the offspring of the high dose caffeine treated group compared to the control group $(\mathrm{P}<0.05)$. The mean
Johnsen scores were showed in fig. 7 and Table 3 at postnatal days 21, 60, and 120 .

Table 3. Estimated Johnsen score results at the postnatal days 21, 60, and 120.

\begin{tabular}{|c|c|c|c|c|}
\hline \multirow{2}{*}{ Parameters } & Age of offspring(day) & \multicolumn{3}{|c|}{ Groups } \\
\cline { 3 - 5 } & & \multirow{2}{*}{ Control } & \multicolumn{2}{|c|}{ Caffeine treated } \\
\hline \multirow{3}{*}{ Johnsen score } & 21 & $9.12 \pm 0.58$ & $8.28 \pm 0.32$ & $7.90 \pm 0.58^{* a}$ \\
& 60 & $9.38 \pm 0.48$ & $8.12 \pm 0.27$ & $7.55 \pm 0.73^{* a}$ \\
\hline
\end{tabular}

Comparison between control and other groups (a), comparison between low dose caffeine treated group and other groups (b) and high dose caffeine treated group and other groups(c). $P<0.05$ is indicated by"*" 


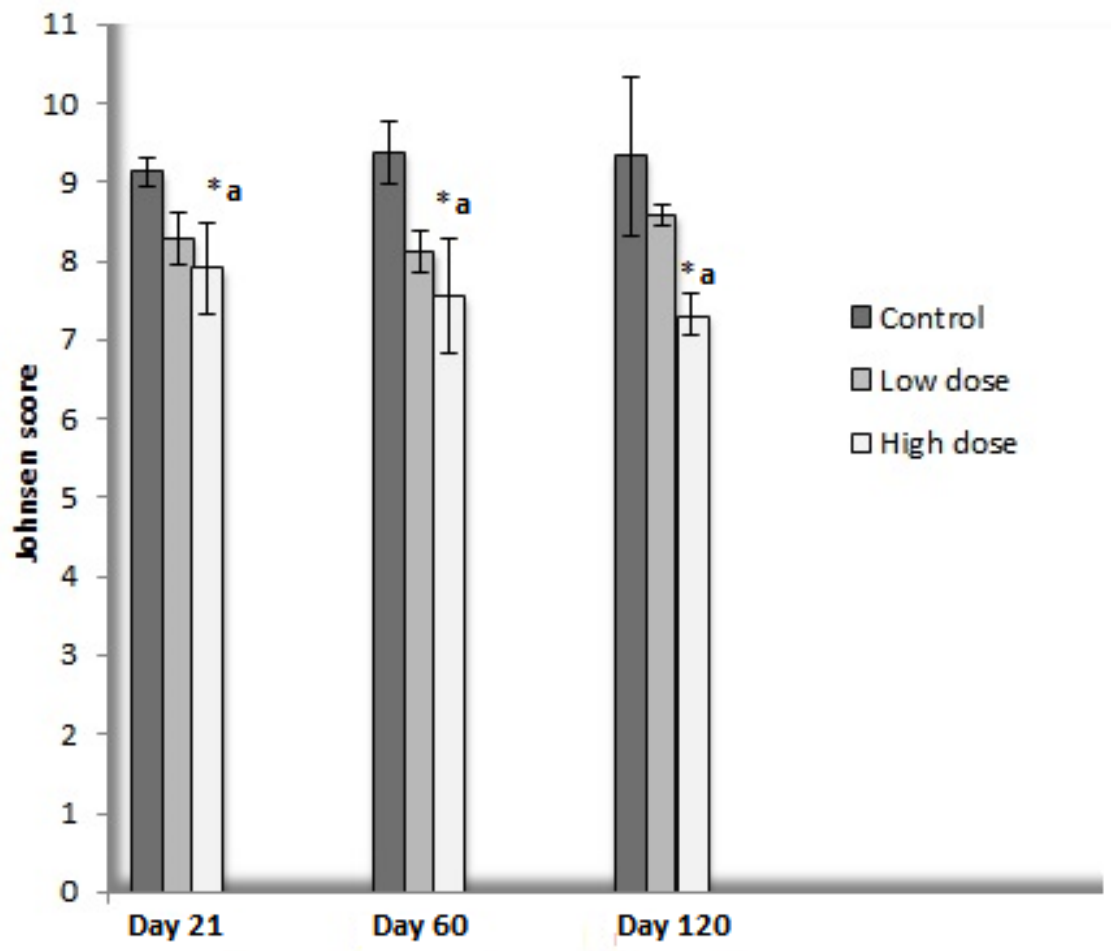

Fig. 7. Mean Johnsen score at the postnatal days 21, 60, and 120. P<0.05 is indicated by"*". Comparison between control and other groups (a), comparison between low dose caffeine treated group and other groups (b) and high dose caffeine treated group and other groups (c).

\section{Histological Findings in the Testis}

No histopathological changes were seen in the offspring of the control group; while an increase in germ cells was found, and the spermatogenesis process was clearly seen. Tubular lumen of the control group showed numerous spermatozoa and the normal interstitial cells were observed in interstitium. The results showed that the seminiferous tubules of the offspring of both experimental groups especially the high dose caffeine-treated group had irregular size and distorted shape and no regular cytoarchitecture but all cells of the spermatogenic series were represented. In this group, some cells were vacuolated in the seminiferous tubule epithelium, and the number of germ cells in the seminiferous tubules was decreased but spermatozoa were clearly observed in the lumen of the tubule. In the testes of the offspring of the high dose caffeinetreated group, some detached and pyknotic round spermatids or retained elongated spermatids were counted. The offspring testes in this group showed a significant reduction in spermatids and spermatozoa especially at day
120. Also, there was a decrease in the height of germinal epithelium in some slides of this group. In the offspring of experimental group 2, the interstitial space between the seminiferous tubules was increased and in some slides displacement of sertoli and germinal cells were seen (Figures 8, 9, 10).

\section{Histological Findings of the Prostate}

No histopathological changes were seen in the control group and there is normal dilatation of prostatic gland. Epithelial and stromal had normal structure in the control group. The microscopic sections of the prostate showed variations in the degree of dilatation in the prostatic gland and in their intra luminal secretions. All the prostates from the offspring of the caffeine-fed rats presented various degrees of epithelial and stromal hyperplasia and epithelial cell proliferation in the prostatic lobes. There appears to be an increased dilatation resulting in the crowding of glands in the offspring of caffeine-fed $(45 \mathrm{mg} / \mathrm{kg})$ in comparison with control group which was statistically significant (Fig. 11). 


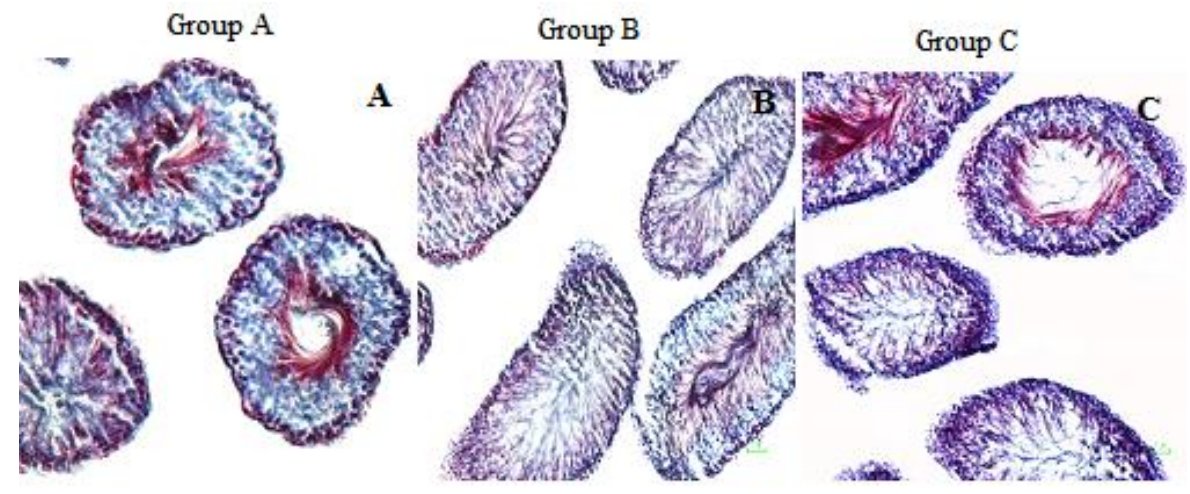

Fig 8. Testis histopathological changes in all groups. A control, B low dose caffeine and C high dose caffeine groups respectively (100x, Heidenhain's Azan).

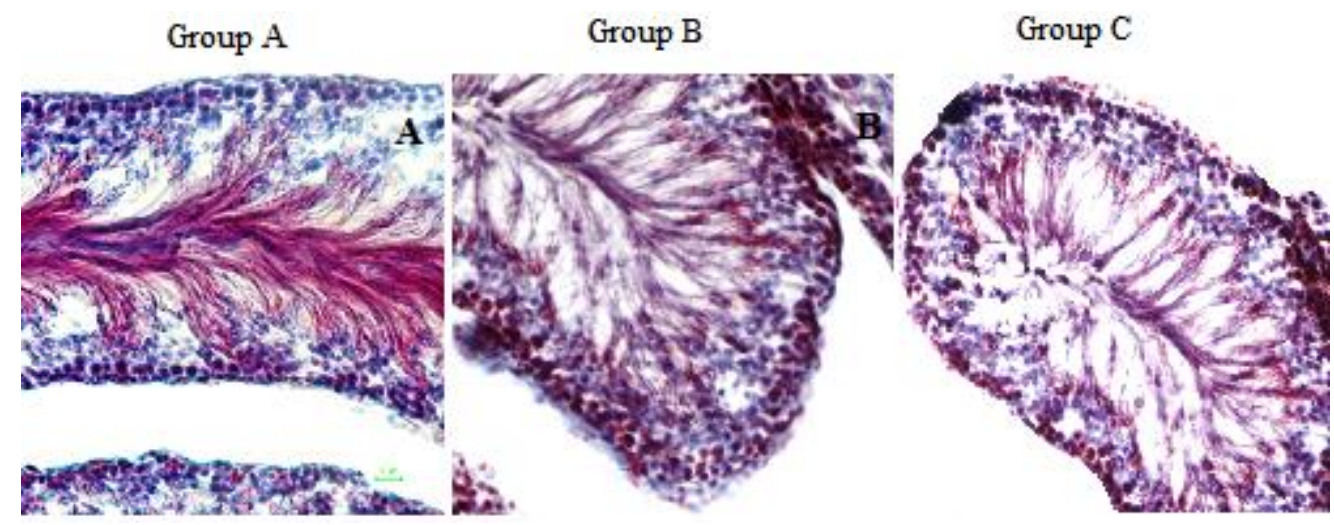

Fig. 9. Testis histopathological changes in all groups. A control, B low dose caffeine and C high dose caffeine groups respectively (200x, Heidenhain's Azan).
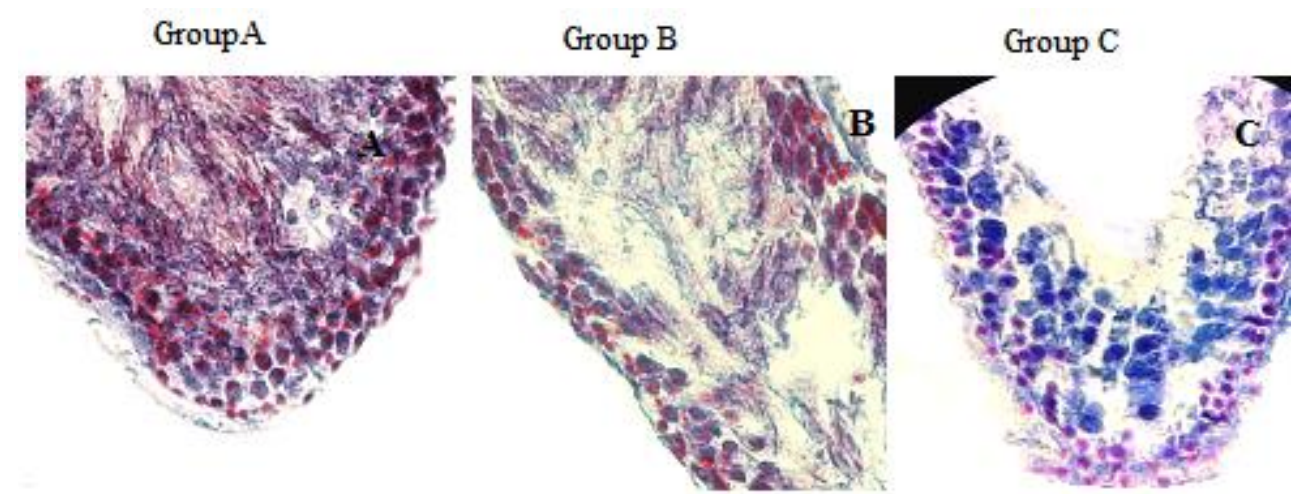

Fig. 10. Testis histopathological changes in all groups. A control, B low dose caffeine and C high dose caffeine groups respectively (400x, Heidenhain's Azan). 


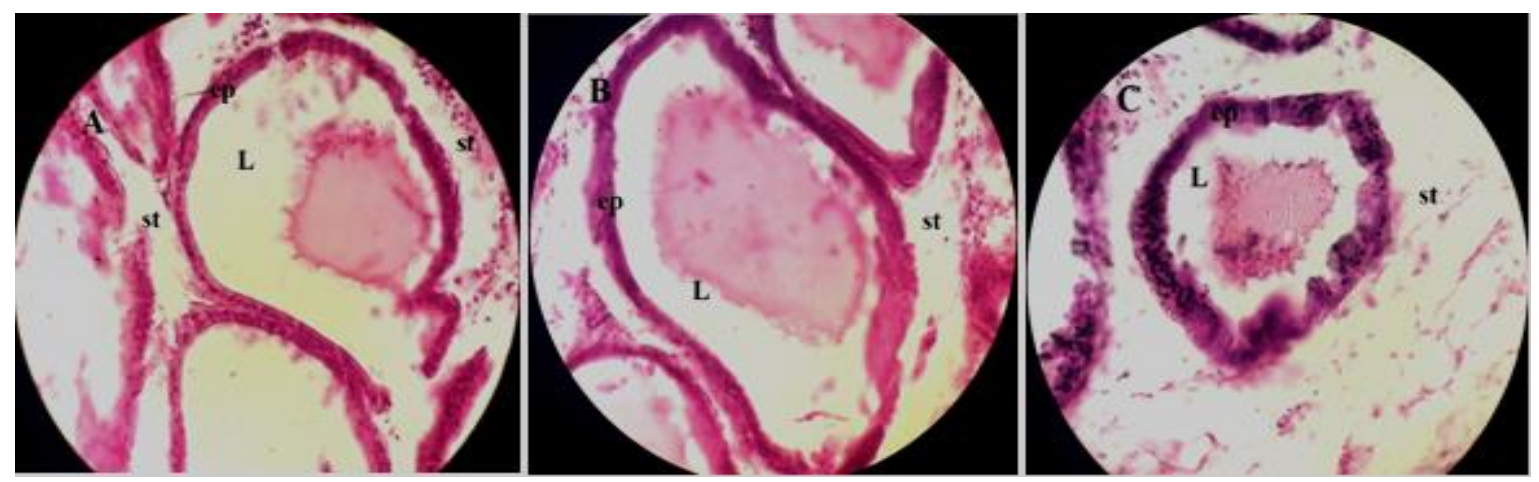

Fig. 11. Prostate histopathological changes at the postnatal day 120. A control, B low dose caffeine and C high dose caffeine groups respectively. st: stroma; I: lumen; ep: epithelium (200x, H\&E).

\section{Discussion}

The present study showed that gestational and lactational exposure to caffeine decreased the body weight, testis weight and testis volume, number of spermatogonia, spermatocyte, spermatid, sperm and sertoli cells of the offspring in the pre-puberty, puberty and post puberty period. In addition, our results indicated that significant decreases in reproductive parameters that have been observed in caffeine-treated offspring were not reversible after the cessation of the exposure period and remained until postnatal day 120 . In this study, significant reductions were seen in body weight in the high dose caffeine treated group compared to the control group and low dose caffeine treated group at all ages of postnatal development. The testis weight of the offspring was significantly lower in the high dose caffeine treated group compared with the control group at days 60 and 120 of postnatal development.

The decrease in body and testis weight of the offspring observed in this study is in consonance with earlier reports. Dorstghoal et al. [17] have examined three groups of female Wistar rats that received caffeine via drinking water during gestation (26 and $45 \mathrm{mg} / \mathrm{kg}$ ) and lactation ( 25 and $35 \mathrm{mg} / \mathrm{kg}$ ). They observed significant dose-related decreases in the body $(11.09 \%)$ and testis weight $(22.56 \%)$ of male offspring rats, at low and high dose caffeine-fed animals, respectively. Also Cavalcant et al. [27] reported that maternal caffeine administration during pregnancy causes a significant reduction in food intake and the body mass gain of the offspring. In addition, caffeine-fed animals consumed less food on average than the control group and there seemed to be a causal relationship between food consumption and body weight. This reduction in body weight of caffeine-fed animals is known to increase metabolic rate and fat oxidation. In contrast, another study found no difference between the caffeine-fed groups and the control group in body and testis weight [28]. This discrepancy may result from differences in doses, administration route, duration of caffeine intake, and age between the studies.

Also, the total testis volume showed significant differences between both experimental groups and the control group at day 21. This parameter in the high dose caffeine-treated group has significantly decreased in comparison with the other groups at days 60 and 120. Previous animal studies also demonstrated that prenatal caffeine exposure reduced the testis volume [29].

In addition, decrease in testis weight and volume of the offspring in the caffeine-fed groups might be due to a decrease in the number of germ cells because the weight and volume of the testis is largely dependent on the mass of the differentiated spermatogenic cells [30]. Also some studies demonstrated that prenatal caffeine exposure inhibited differentiation of the seminiferous tubules [31] and decreased the diameter of seminiferous tubules [18] and reduced in this cases lead to reductions in testis weight and volume.

Pollard et al. [32] noted that gestational caffeine consumption can be significantly inhibit differentiation of the seminiferous tubules. Pollard and Small also [33] reported 
that exposure of male Wistar rats to 30 $\mathrm{mg} / \mathrm{kg} /$ day of caffeine, for 15 to 38 days led to a breakdown of the germinal epithelium. In fact, they reported that it seems that caffeine, by decreasing the spermatogenesis, led to a decrease in the high level of germinal epithelium and seminiferous tubule diameter. Also caffeine reduced the seminiferous tubule diameter by contraction of smooth muscles around the tubules [34].

Our investigation revealed that caffeine decreased the number of spermatogonia, spermatocyte, spermatid, sperm and sertoli cells of offspring male rats. Several animal studies have also demonstrated a negative influence of caffeine on the number of spermatogenic and sertoli cells [18, 29]. Caffeine seems to interfere with cell division, resulting in a reduced number of spermatogenic cells [35]. In fact caffeine, by its negative effect on proliferation of sertoli cells, can reduce the performance of spermatogenesis in the male offspring of caffeine-fed rats [36].

In the present study, histopathologic evaluation showed that the mean Johnsen score was decreased in the high dose caffeine treated group compared to the control group at postnatal days 21,60 , and 120 . There were differences in the Johnsen score between the low dose caffeine treated group and the control group, but this difference is not significant. It means that caffeine had significant dose-related decreases in the spermatogenesis process and tubules.

In the current study, we examined the effects of gestational and lactational caffeine consumption on prostate glands of male offspring. There was an increase in the total prostate weight and size in the caffeine treated groups compared to the control group at postnatal days 21, 60 and 120. Also, our results showed various degrees of epithelial and stromal hyperplasia and epithelial cell proliferation in the prostatic lobes of caffeine fed animals. The prostatic hyperplasia in caffeine-treated animals observed in our study may be related to several different factors, one of which may be plasma androgen levels. Although the role of androgens as the causative factor for BPH (benign prostate hyperplasia) is debated, it undoubtedly plays, at least, a permissive role in the process $[37,38]$.

In this regard Sarobo et al. [20] reported that the exposure of male Wistar rats to $20 \mathrm{ppm}$ per day of caffeine, in drinking water for 140 day caused epithelial cell proliferation. This epithelial cell proliferation associated with increased AR (androgenic receptor) tissue staining observed in the VP (ventral prostate), strongly suggests that caffeine intake increases androgenic signaling in the VP epithelial cells, increasing their proliferative and secretory activities and inducing abnormal hyperplasic prostate growth. This can also be related to the development of BPH. Our results are in agreement with Sarobo et al results.

\section{Conclusion}

In conclusion, gestational and lactational exposure to caffeine may impact gonadal maturation and later gonadal function. We confirmed that caffeine reduced testis growth and altered testis histomorphology. Our results demonstrated that caffeine exposure during gestation and lactation had irreversible effects on the testis performance of male offspring rats and altered the testicular micro architecture and also slowed the negative effects on germ cell proliferation even at the $26 \mathrm{mg} / \mathrm{kg}$. As the lowest dose adopted in this study also affected parameters related to sexual maturation, further studies using a larger number of animals, as well as females, are required to determine the minimal safe dose of caffeine.

\section{Acknowledgements}

This paper is extracted from the MSc thesis of Mahboubeh Belali kharaji and financially supported by Shahid Sadoughi University of Medical Sciences, Yazd, Iran. The authors would like to thank the Department of Anatomical Sciences and Faculty of Medicine for official cooperation.

\section{Conflicts of interest}

The authors state no conflicts of interest in this study. 


\section{References}

1. Feng HL. Molecular biology of male infertility. Arch Androl. 2003;49(1):19-27.

2. Yadegari M, Khazaei M, Hamzavi Y, Toloei AR. Antifertility effects of Falcaria vulgaris in female rat. Arak Medical University Journal. 2011;14(2).

3. Brent RL, Christian MS, Diener RM. Evaluation of the reproductive and developmental risks of caffeine. Birth Defects Res B Dev Reprod Toxicol. 2011;92(2):152-87.

4. Verbeeck RK. Pharmacokinetics and dosage adjustment in patients with hepatic dysfunction. Eur J Clin Pharmacol. 2008;64(12):1147-61.

5. Zajac MA, Zakrzewski AG, Kowal MG, Narayan S. A novel method of caffeine synthesis from uracil. Synthetic communications. 2003;33(19):3291-7.

6. Nehlig A, Debry G. Potential teratogenic and neurodevelopmental consequences of coffee and caffeine exposure: a review on human and animal data. Neurotoxicol Teratol. 1994;16(6):531-43.

7. Heatherley S, Mullings E, Tidbury M, Rogers P. Caffeine consumption among a sample of UK adults. Appetite. 2006;47(2):266.

8. Liguori A, Hughes JR, Grass JA. Absorption and subjective effects of caffeine from coffee, cola and capsules. Pharmacol Biochem Behav. 1997;58(3):721-6.

9. Knutti R, Rothweiler H, Schlatter C. Effect of pregnancy on the pharmacokinetics of caffeine. Eur $\mathrm{J}$ Clin Pharmacol. 1981;21(2):121-6.

10. Fredholm BB, Bättig K, Holmén J, Nehlig A, Zvartau EE. Actions of caffeine in the brain with special reference to factors that contribute to its widespread use. Pharmacological reviews. 1999;51(1):83-133.

11. Goldstein A, Warren R. Passage of caffeine into human gonadal and fetal tissue. Biochemical pharmacology. 1962;11(2):166-8.

12. Bakker R, Steegers EA, Obradov A, Raat H, Hofman A, Jaddoe VW. Maternal caffeine intake from coffee and tea, fetal growth, and the risks of adverse birth outcomes: the Generation R Study. Am J Clin Nutr. 2010;91(6):1691-8.

13. Yadegari M, Khazaei M, Anvari M, Eskandari M. Prenatal Caffeine Exposure Impairs Pregnancy in Rats. Int J Fertil Steril. 2016;9(4):558-62.

14. Tinwell H, Colombel S, Blanck O, Bars R. The screening of everyday life chemicals in validated assays targeting the pituitary-gonadal axis. Regulatory Toxicology and Pharmacology. 2013;66(2):184-96.

15. Ramlau-Hansen CH, Thulstrup AM, Bonde JP, Olsen J, Bech BH. Semen quality according to prenatal coffee and present caffeine exposure: two decades of follow-up of a pregnancy cohort. Hum Reprod. 2008;23(12):2799-805.

16. Friedman L, Weinberger MA, Farber TM, Moreland FM, Peters EL, Gilmore CE, et al. Testicular atrophy and impaired spermatogenesis in rats fed high levels of the methylxanthines caffeine, theobromine, or theophylline. J Environ Pathol Toxicol. 1979;2(3):687-706.

17. Dorostghoal M, Majd NE, Nooraei P. Maternal caffeine consumption has irreversible effects on reproductive parameters and fertility in male offspring rats. Clinical and experimental reproductive medicine. 2012;39(4):144-52.

18. Bae J, Choi H, Choi Y, Roh J. Dose- and time-related effects of caffeine on the testis in immature male rats. Exp Anim. 2017;66(1):29-39.

19. Dias TR, Alves MG, Bernardino RL, Martins AD, Moreira AC, Silva J, et al. Dose-dependent effects of caffeine in human Sertoli cells metabolism and oxidative profile: relevance for male fertility. Toxicology. 2015;328:12-20.

20. Sarobo C, Lacorte LM, Martins M, Rinaldi JC, Moroz A, Scarano WR, et al. Chronic caffeine intake increases androgenic stimuli, epithelial cell proliferation and hyperplasia in rat ventral prostate. Int J Exp Pathol. 2012;93(6):429-37.

21. Arab L, Su LJ, Steck SE, Ang A, Fontham ET, Bensen JT, et al. Coffee consumption and prostate cancer aggressiveness among African and Caucasian Americans in a population-based study. Nutrition and cancer. 2012;64(5):637-42.

22. Odum J, Lefevre PA, Tinwell H, Van Miller JP, Joiner RL, Chapin RE, et al. Comparison of the developmental and reproductive toxicity of diethylstilbestrol administered to rats in utero, lactationally, preweaning, or postweaning. Toxicol Sci. 2002;68(1):147-63.

23. Dehghani F, Hassanpour A, Poost-Pasand A, Noorafshan A, Karbalay-Doust S. Protective effects of L-carnitine and homogenized testis tissue on the testis and sperm parameters of busulfan-induced infertile male rats. Iran J Reprod Med. 2013;11(9):693-704. 
24. Mahmoudi R, Honarmand Z, Karbalay-Doust S, Jafari-Barmak M, Nikseresht M, Noorafshan A. Using curcumin to prevent structural impairments of testicles in rats induced by sodium metabisulfite. EXCLI journal. 2017;16:583.

25. Dortaj H, Yadegari M, Hosseini Sharif Abad M, Abbasi Sarcheshmeh A, Anvari M. Effects of Acrylamide and Vitamin $\mathrm{C}$ on Histological Changes and Stereological Parameters of Cerebellum in Rat Offsprings. The Neuroscience Journal of Shefaye Khatam. 2014;2(3):9-18.

26. Bertram JF. Analyzing renal glomeruli with the new stereology. Int Rev Cytol. 1995;161:111-72.

27. Cavalcante FS, Aiceles V, Moraes DdFS, AlvesPereira JL, Faria TS, Ramos CdF. The testis of the mice C57/BL6 offspring in adulthood have alterations due to maternal caffeine consumption. Acta Cirurgica Brasileira. 2014;29(1):16-23.

28. Inoue H, Kobayashi-Hattori K, Horiuchi Y, Oishi Y, Arai S, Takita T. Regulation of the body fat percentage in developmental-stage rats by methylxanthine derivatives in a high-fat diet. Biosci Biotechnol Biochem. 2006;70(5):1134-9.

29. Oluwole OF, Salami SA, Ogunwole E, Raji Y. Implication of caffeine consumption and recovery on the reproductive functions of adult male Wistar rats. J Basic Clin Physiol Pharmacol. 2016;27(5):483-91.

30. Mruk DD, Cheng CY. Sertoli-Sertoli and Sertoligerm cell interactions and their significance in germ cell movement in the seminiferous epithelium during spermatogenesis. Endocrine reviews. 2004;25(5):747-806.
31. Pollard I, Williamson S, Magre S. Influence of caffeine administered during pregnancy on the early differentiation of fetal rat ovaries and testes. J Dev Physiol. 1990;13(2):59-65.

32. Pollard I, Locquet O, Solvar A, Magre S. Effects of caffeine and its reactive metabolites theophylline and theobromine on the differentiating testis. Reprod Fertil Dev. 2001;13(5-6):435-41.

33. Pollard I, Smallshaw J. Male mediated caffeine effects over two generations of rats. J Dev Physiol. 1988;10(3):271-81.

34. Arabi M. Study of effects of acute and chronic doses of Caffeine on hormonal axis of PG and testis in adult male rat: MSc Thesis] Tehran: Tarbiat Moallem University of Tehran; 1993.

35. Kaukab N, Saeed M. Effects of caffeine on rat testes. Prof Med J. 1999;6:1-5.

36. Kerr JB, Knell CM. The fate of fetal Leydig cells during the development of the fetal and postnatal rat testis. Development. 1988;103(3):535-44.

37. Bartsch G, Rittmaster R, Klocker H. Dihydrotestosterone and the concept of 5a-reductase inhibition in human benign prostatic hyperplasia. World journal of urology. 2002;19(6):413-25.

38. Ho CK, Habib FK. Estrogen and androgen signaling in the pathogenesis of BPH. Nat Rev Urol. 2011;8(1):29-41.

\section{How to Cite This Article:}

Belali Kharaji M, Yadegari M, Hosseini Sharif abad M, Anvari M, Abbasi Sarcheshmeh A, Dortaj H. Stereological Study on the Effects of Maternal Caffeine Consumption on Histomorphometric Changes of Testis and Prostate in Rat Offspring . Mod Med Lab J. 2020; 3 (1) :46-59 